\title{
ANALISIS HUBUNGAN KEBISINGAN MESIN DENGAN STRES KERJA (Studi Kasus : Mesin TWO FOR ONE TWISTER (TFO) PT. XYZ)
}

\author{
Wiwik Budiawan ${ }^{1 *}$, Ema Amalia Ulfa ${ }^{1}$, Pertiwi Andarani ${ }^{2}$ \\ ${ }^{1}$ Program Studi Teknik Industri, Fakultas Teknik, Universitas Diponegoro \\ 2Program Studi Teknik Lingkungan, Fakultas Teknik, Universitas Diponegoro \\ JI. Prof. Soedarto, SH, Kampus Undip Tembalang, Semarang, Indonesia 50275 \\ Email: *wiwikbudiawan@ft.undip.ac.id
}

\begin{abstract}
The Two for One Twister (TFO) machine emits very disturbing noise and the noise exposes the workers while performing their tasks. The noise also lead to works stress. So, it is necessary to determine the relationship between the noise and work stress of TFO machine operators. This study was conducted by measuring the noise of TFO engine with Enviro-meter and then correlating the noise and work stress with SPSS 16 software. Spearman correlation test results showed that a strong correlation between noise with work stress ( $p$ value $=0.042$ ). In order to reduce the noise level that will decrease stress for workers, Fault Tree Analysis was conducted to determine the source of the noise. Based on the qualitative analysis of FTA, the causes of the noise were as follows: the lubricating oil was not applied, seal of oil valve leaked, bearing was not replaced (2 years economic life), the traveler was not replaced (10 days economic life), and the Doubling machine was troubled. Based on the quantitative analysis of the probability of job stress of TFO machine operator due to noise TFO machines from a known probability of 0.041 , hence, the system was feasible for use.
\end{abstract}

Key words: Noise, Work Stress, Spearman Correlation Test, Fault Tree Analysis

\section{PENDAHULUAN}

Kebisingan merupakan masalah yang hampir selalu dijumpai di semua tempat kerja. Baru-baru ini, polusi suara telah menjadi perhatian seluruh dunia karena yang merugikan efek pada kesejahteraan fisiologis dan psikologis orang. Efek kesehatan dari polusi suara termasuk gangguan pendengaran, gangguan komunikasi, gangguan tidur, penurunan kinerja karyawan, gangguan kognitif pada anak-anak, dan penyakit kardiovaskuler (WHO, 2011). Menurut Occupational Safety and Health Administration (OSHA) Standards-29CFR, nilai level kebisingan 90 dBA (low) untuk 8 jam kerja. Paparan kebisingan dengan intensitas yang tinggi melebihi Nilai Ambang Batas yang ditetapkan pemerintah melalui KEPMENAKER No. 51/MEN/1999 (85 dB untuk paparan 8 jam kerja sehari) akan membahayakan kesehatan pada telinga tenaga kerja. Efek kebisingan dengan intensitas tinggi terhadap pendengaran berupa ketulian syaraf (Noise Induced Hearing Loss) tersebut telah banyak diteliti. Namun, kebisingan selain memberikan efek terhadap pendengaran (auditory effects) juga dapat menimbulkan efek bukan pada pendengaran (non auditory effects) dan efek ini bisa terjadi walaupun intensitas kebisingan tidak terlalu tinggi. Efek non auditori terjadi karena bising dianggap sebagai suara yang mengganggu sehingga respons yang timbul adalah akibat stres bising tersebut.

Stres yang diakibatkan kerja dapat muncul jika tuntutan lingkungan kerja melebihi kemampuan pekerja untuk mengatasi atau mengontrolnya (EU-OSHA, 2005). Sumber penyebabnya adalah dari gangguan stres dari pekerjaan itu sendiri, tetapi dapat juga disebabkan adanya stressor fisik, emosional, dan mental. 
Banyak stressor yang berhubungan dengan kerja dan sangat jarang ditemukan hanya terdapat satu faktor penyebab stres akibat kerja (EU-OSHA, 2005). Stressor fisik di tempat kerja, contohnya seperti kebisingan (Harrianto, 2010).

Menurut NIOSH (2010), penyakit akibat kebisingan kerja ditemukan pada 17.700 kasus dari 59.100 kasus, yaitu sejumlah 1 dari 9 penyakit akibat kerja yang dilaporkan. Menurut penelitian Nawawinetu dan Adriyani (2007) yang dilakukan di perusahaan penggilingan padi di Desa Metatu Surabaya, sebanyak $66,67 \%$ karyawan yang merasa sedikit terganggu oleh suara bising dan $8,33 \%$ yang sangat terganggu. Intensitas kebisingan di perusahaan tersebut berkisar antara 93-98 dB dengan nilai rerata 95,58 dB dan simpangan baku 1,822. Responden bekerja selama 7,5 jam kerja dengan 1 jam istirahat. Penelitian yang dilakukan Halil, dkk (2009) terhadap karyawan di bagian operator mesin pembangkit listrik PLN Sektor Tello Makassar didapatkan sebanyak $83,3 \%$ mengalami stres ringan, stres sedang $10,6 \%$, dan stres berat $6,1 \%$. Hal ini disebabkan oleh karyawan di bagian operator mesin setiap hari terpapar kebisingan. Dan juga tingkat kebisingan di PLN Sektor Tello Makassar di atas ambang batas.

Dalam lingkup ketenagakerjaan, stres kerja merupakan masalah bagi kesehatan tenaga kerja, berpotensi meningkatkan risiko kecelakaan kerja yang akan menimbulkan banyak kerugian materi, dan mampu menurunkan produktivitas secara keseluruhan. Kondisi individual juga berpengaruh terhadap terjadinya stres kerja. Seorang individu menilai suatu situasi menimbulkan stres atau tidak, sangatlah tergantung dari kepekaan individu dari mencakup beberapa variabel diantaranya usia, masa kerja, komunikasi di tempat kerja, kepribadian dan semangat kerja.

Perusahaan yang menjadi obyek yaitu PT. $X Y Z$, perusahaan ini bergerak dalam industri pemintalan benang, yang berlokasi di Kabupaten Pekalongan. Pabrik ini sendiri terdiri dari Spinning 1, Spinning 2, dan Spinning 3. Mesin Two For One Twister (TFO) memproses benang Twisted. Sebanyak 26 Mesin TFO dengan operator sebanyak 18 orang yang terdapat di Spinning 1 yang menghasilkan suara bising yang sangat menganggu ketika beroperasi. Dengan suara mesin yang gaduh dan waktu kerja 8 jam/hari secara terus-menerus dapat menyebabkan adanya gangguan operator (kebisingan). Kebisingan dapat menimbulkan efek berupa gangguan fisiologis, psikologis dan gangguan patologis organis, salah satu contoh gangguan psikologis yang diakibatkan oleh kebisingan adalah stres kerja.

\section{LAYOUT MESIN TWO FOR ONE TWISTER (TFO)}

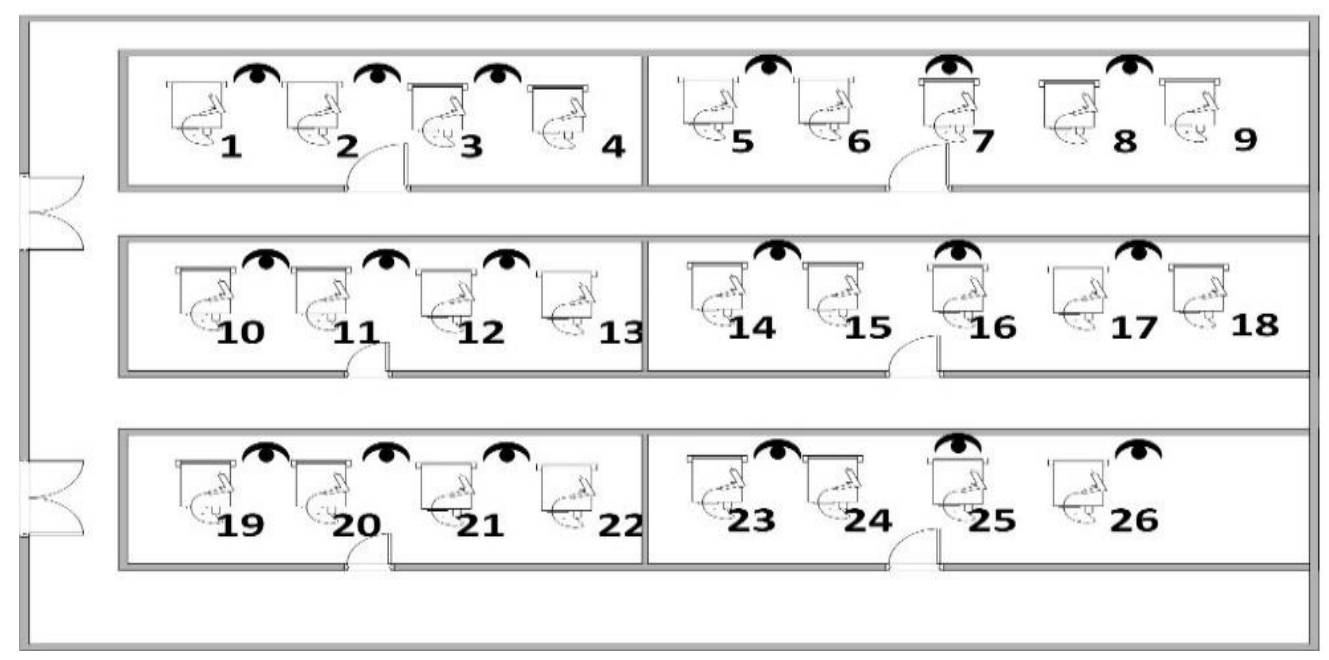

Gambar 1. Layout Mesin TFO dan titik pengukuran kebisingan

Oleh karena itu, berdasarkan kenyataan di lapangan perlu dilakukan pengukuran mengenai kebisingan di mesin TFO dengan Enviro meter kemudian dilakukan uji 
Korelasi Spearman dengan software SPSS 16 untuk mengetahui hubungan kebisingan dengan stres kerja operator mesin TFO. Setelah itu dilakukan analisis menggunakan Fault Tree Analysis sumber kebisingan untuk mengetahui sumber kebisingan sehingga diharapkan dapat digunakan untuk mengurangi tingkat kebisingan yang dihasilkan mesin TFO sehingga tidak menyebabkan stres kerja operator mesin TFO.

\section{METODOLOGI}

\section{Objek Penelitian}

Jenis penelitian yang digunakan adalah penelitian analitik dengan rancangan cross sectional study. Penelitian ini dilaksanakan di PT XYZ, yang dilakukan pada bulan Agustus 2015. Populasi mesin TFO adalah 26 mesin setiap 4-5 mesin dan 3 orang berada pada 1 ruangan. Populasi operator mesin TFO yaitu sebanyak 18 operator. Pengumpulan data dilakukan dengan pengambilan data primer, yaitu pengambilan data stres kerja dengan kuisioner dan pengukuran intensitas kebisingan pada 26 mesin TFO menggunakan alat Envirometer dengan 30 kali pengambilan data untuk setiap mesin

Gambar 1 adalah.layout mesin TFO dan 26 titik pengukuran kebisingan. Dari titik pengukuran tersebut kemudian dirata-rata untuk setiap ruangan. Setelah diperoleh hasil pengukuran kebisingan dan kuesioner stres kerja, dilakukan uji kecukupan dan keseragaman data.

$$
\text { Uji kecukupan data , }
$$

$$
\mathrm{N}^{s}=\left[\frac{\frac{\mathrm{k}}{\mathrm{g}} \sqrt{\mathrm{N} \sum_{i=1}^{W} x_{i}^{2}-\left(\sum_{i=}^{W}\right.}}{\sum_{i=1}^{\mathscr{W}} x_{i}}\right.
$$

Jika $\mathrm{N}>\mathrm{N}^{\prime}$, maka data cukup

- Uji Keseragaman Data

$$
\begin{aligned}
-\mathrm{SD} & =\sqrt{\frac{\sum_{i=1}^{W}\left(x_{i}-\mathrm{xk}\right)^{2}}{\mathrm{~N}-1}} \\
\overline{\overline{\mathrm{x}}} & =\frac{\sum_{i=1}^{N} x_{\bar{i}}}{\mathrm{~N}} \\
\mathrm{BKA} & =\overline{\overline{\mathrm{X}}}+(\mathrm{k} * \mathrm{SD}) \\
\mathrm{BKB} & =\overline{\overline{\mathrm{x}}}-(\mathrm{k} * \mathrm{SD})
\end{aligned}
$$

dimana, $\mathrm{N}^{\prime}=$ jumlah pengamatan yang seharusnya dilakukan; $\mathrm{K}=$ tingkat kepercayaan dalam pengamatan $(k=2,1$ $\alpha=95 \%) ; S=$ derajat ketelitian pengamatan $(5 \%) ; \mathrm{N}=$ jumlah pengamatan yang sudah dilakukan; = data pengamatan; = nilai ratarata; $\mathrm{SD}=$ standar deviasi; $\mathrm{BKA}=$ batas atas; $\mathrm{BKB}=$ batas bawah.

Untuk mengetahui hubungan antara kebisingan dan stres kerja maka dilakukan uji korelasi Spearman dengan menggunakan software SPSS 16. Uji korelasi Spearman ini digunakan karena uji ini digunakan untuk mengetahui hubungan antara 2 variabel peubah. dalam kasus ini kebisingan dengan stres kerja sehingga menggunakan korelasi dan data $\mathrm{n}<30$. Dengan Hipotesis sebagai berikut :

$$
\begin{aligned}
& \text { 1. } H_{0}==0 \\
& \text { 2. } H_{1}=>0 \\
& \text { 3. }=0.05 \\
& \text { 4. Daerah kritis : Sig. (2-tailed) }<0.05
\end{aligned}
$$

Dengan menggunakan uji korelasi spearman besarnya korelasinya bisa diketahui dari koefisien korelasi. Jika koefisien korelasi mendekati 1 , hubungan antara 2 variabel peubah kuat. Selain itu, Significant 2-tailed (dwi sisi) ( $\mathrm{p}$-value) $<0.05$ menunjukkan adanya hubungan antara 2 variabel peubah kuat

\section{Fault Tree Analysis}

Setelah dilakukan pengukuran mengenai kebisingan di mesin TFO dengan Enviro meter kemudian dilakukan uji Korelasi Spearman dengan software SPSS 16 untuk mengetahui hubungan kebisingan dengan stres kerja operator mesin TFO. Kemudian dilakukan analisis dengan menggunakan metode Fault Tree Analysis. Metode ini sering digunakan untuk menganalisis kegagalan sistem. Fault Tree Analysis (FTA) adalah metode analisis, dimana terdapat suatu kejadian yang tidak diinginkan disebut undesired event tejadi pada sistem, dan sistem tersebut kemudian dianalisis dengan kondisi lingkungan dan operasional yang ada untuk menemukan semua cara yang mungkin terjadi yang mempengaruhi pada terjadinya undesired event tersebut (Vesely dan Goldberg, 1981). Pada kasus ini FTA digunakan untuk menganalisis penyebab kebisingan pada mesin TFO. Pada dasarnya penyebab kebisingan pada mesin TFO adalah mesin rusak dan material input, dan kemudian 
Budiawan,W., Ulfa, E. A., Andarani, P.

Analisis Hubungan Kebisingan Mesin Dengan Stres

Kerja

dilakukan analisis kebisingan dengan menggunakan Fault Tree Analysis untuk mengetahui sumber kebisngan sehingga diharapkan dapat digunakan untuk mengurangi tingkat kebisingan yang dihasilkan mesin TFO sehingga tidak menyebabkan stres kerja operator mesin TFO.

\section{HASIL DAN PEMBAHASAN}

Data hasil kebisingan yang diperoleh dari 26 mesin dan data hasil kuesioner stres kerja operator mesin TFO dapat dilihat pada Tabel 1.

Setelah hasil pengukuran dan kuesioner diperoleh, perlu dilakukan uji kecukupan dan keseragaman data. Dari hasil uji kecukupan data, diperoleh $\mathrm{N}^{\prime}=24,17$ sehingga jumlah data yang diambil cukup ( $N>24,17)$. Berdasarkan uji keseragaman data, diperoleh standard deviasi (SD) 1,25 dan = 101,66 sehingga $\mathrm{BKA}=104,15$ dan $\mathrm{BKB}=$ 99,17 . Dengan demikian, seluruh data yang diambil telah seragam karena berada dalam range antara 99,17 sampai 104,15.

Tabel 1. Hasil Pengukuran

\begin{tabular}{ccc}
\hline No & $\begin{array}{c}\text { Rata-rata } \\
\text { Kebisingan } \\
\text { Mesin TFO }\end{array}$ & $\begin{array}{c}\text { Rata -rata } \\
\text { Stres Kerja }\end{array}$ \\
\hline $\mathbf{1}$ & 99,65 & 62,00 \\
$\mathbf{2}$ & 100,65 & 60,33 \\
$\mathbf{3}$ & 101,49 & 69,67 \\
$\mathbf{4}$ & 101,84 & 67,67 \\
$\mathbf{5}$ & 102,50 & 78,33 \\
$\mathbf{6}$ & 103,22 & 74,33 \\
\hline
\end{tabular}

Berdasarkan Uji korelasi Spearman dengan menggunakan software SPSS 16, diperoleh hasil bahwa tingkat kebisingan mesin TFO dengan stres kerja operator mesin TFO memiliki hubungan yang kuat dengan correlation Coeficient mendekati 1 yaitu 0,829 dan Significant 2-tailed (dwi sisi) (p-value) $<0.05$, yaitu 0,042 .

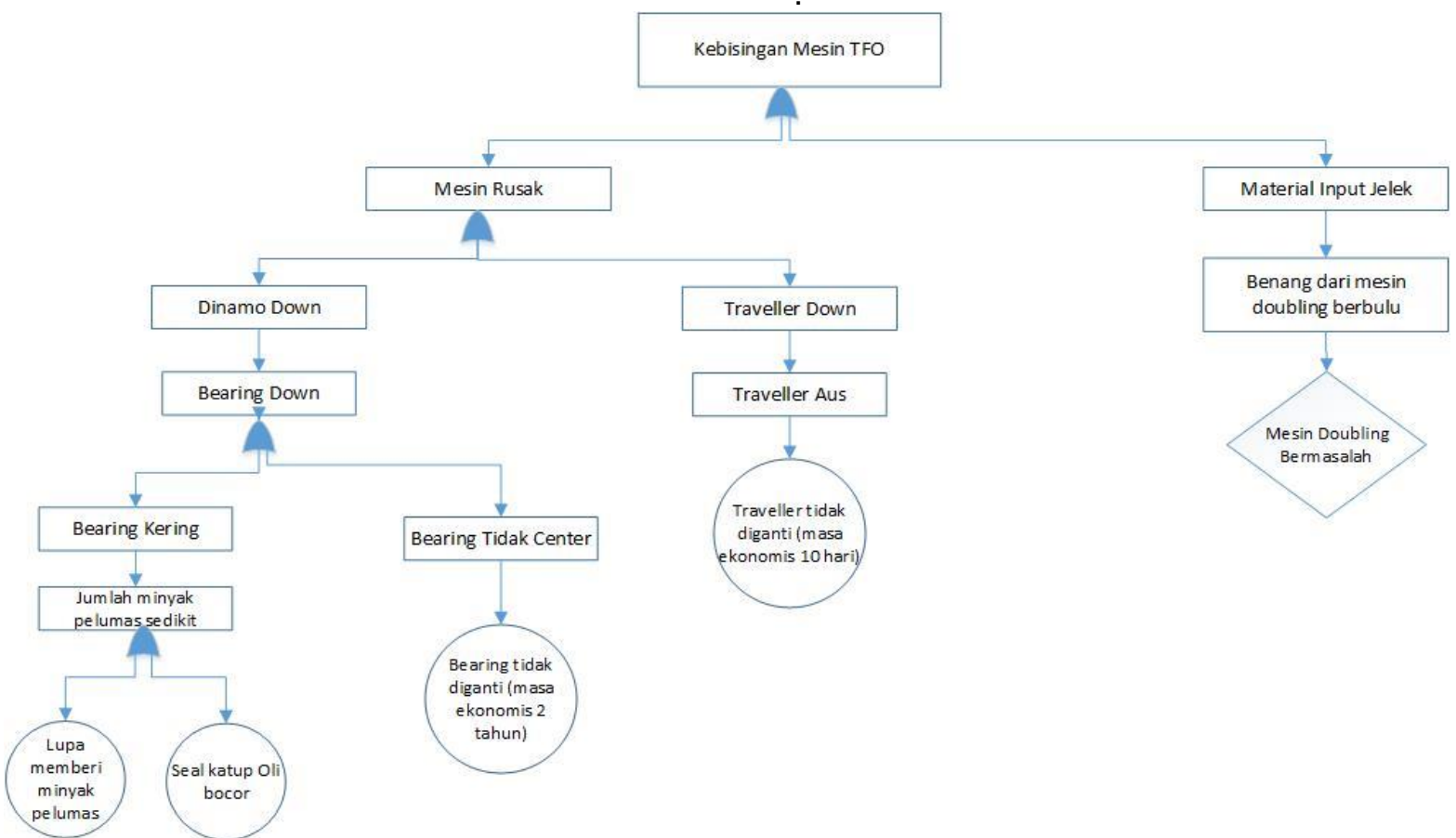

Gambar 2. Fault Tree Analysis sumber kebisingan Mesin TFO

Adanya hubungan yang kuat antara tingkat kebisingan mesin TFO dengan stres kerja operator mesin TFO, tentunya terpengaruh terhadap masalah kesehatan tenaga kerja, sehingga berpotensi meningkatkan risiko kecelakaan kerja yang akan menimbulkan banyak kerugian materi, dan mampu menurunkan produktivitas secara keseluruhan. Sehingga untuk mencegah terjadinya hal tersebut, perlu dilakukan upaya untuk mengurangi tingkat kebisingan sehingga akan menggurangi 
stres kerja bagi para pekerja. Dengan menggunakan analisis menggunakan Fault Tree Analysis (FTA) sumber kebisingan untuk mengetahui sumber kebisingan sehingga diharapkan dapat digunakan untuk mengurangi tingkat kebisingan yang dihasilkan mesin TFO sehingga tidak menyebabkan stres kerja operator mesin TFO.

Data penyebab kebisingan diperoleh dari hasil wawancara dengan Kepala Maintenance, data tersebut akan digunakan sebagai acuan untuk membuat FTA. Gambar 2 merupakan FTA dari kasus ini

Untuk menganalisis secara kualitatif dan kuantitatif dari FTA diatas, akan dicari dahulu minimal cut set-nya dengan menggunakan aljabar boolean. Setelah didapat minimal cut set, analisis kualitatif akan mendapatkan kegagalan yang mengarah langsung pada terjadinya top event dan analisis kuantitatif dengan menggunakan teori probabilitas akan didapatkan probabilitas to event terjadi.

Cut set adalah himpunan basic event dimana jika terjadi semua basic event tersebut muncul, akan terjadi top event. Minimal cut set adalah himpunan kombinasi terkecil dari basic event dimana jika basic event tersebut terjadi, akan menyebabkan top event terjadi (Vesely dkk, 1981).

Permisalan :

T adalah Top event

$P$ adalah Primary Event (Basic event)

$G$ adalah intermediate event

$\mathrm{S}$ adalah undevelopment event

$\mathrm{C}$ adalah conditioning event

Dimisalkan

$\mathrm{T}=$ Kebisingan Mesin TFO (Top event)

G1 = Mesin Rusak

G2 = Material input jelek

G3 = Dinamo Down

G4 = Traveller Down

G5 = Benang dari mesin Doubling berbulu

$\mathrm{S} 1=$ Mesin Doubling bermasalah

G6 = Bearing Down

G7 = Traveller Aus

G8 = Bearing Kering

G9 = Bearing Tidak Center

$\mathrm{P1}=$ Traveller tidak diganti (masa ekonomis 10 hari)

G10 = Jumlah Minyak pelumas sedikit

$\mathrm{P} 2$ = Lupa memberi minyak pelumas

P3 = Seal Katup Oli Bocor

P4 = bearing tidak diganti (masa ekonomis 2 tahun)

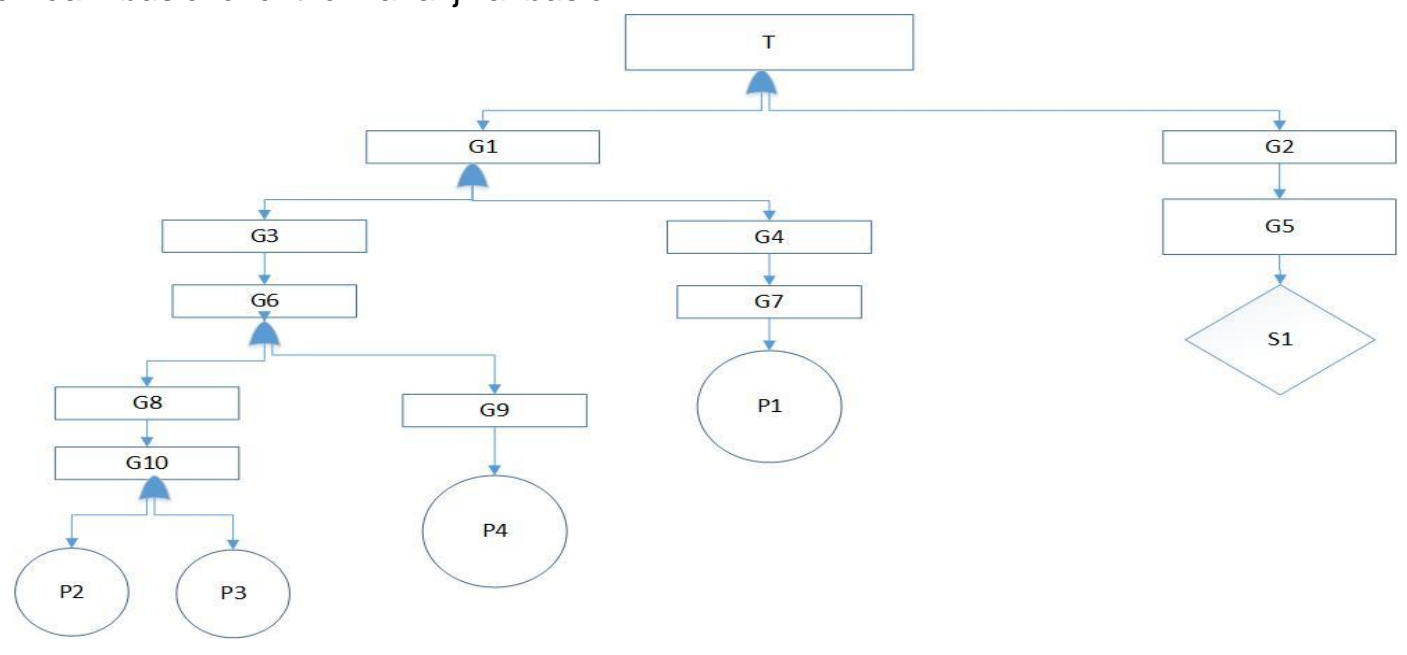

Gambar 3. Fault Tree Analysis dengan Permisalan

Dengan menempatkan tiap permisalan pada gambar Fault Tree Analyis maka akan diperoleh FTA seperti pada Gambar 3.

Dari gambar tersebut bisa didapat persamaan Booleannya :

$$
\begin{array}{ll}
\mathrm{T} & =\mathrm{G} 1+\mathrm{G} 2 \\
\mathrm{G} 1 & =\mathrm{G} 3+\mathrm{G} 4 \\
\mathrm{G} 2 & =\mathrm{G} 5=\mathrm{S} 1
\end{array}
$$

$$
\begin{array}{lll}
\text { G3 } & =\mathrm{G} 6 & =\mathrm{G} 8+\mathrm{G} 9 \\
\mathrm{G} 8 & =\mathrm{G} 10 & =\mathrm{P} 2+\mathrm{P} 3 \\
\mathrm{G} 9 & =\mathrm{P} 4 & \\
\mathrm{G} 4 & =\mathrm{G} 7 & =\mathrm{P} 1
\end{array}
$$

Dengan menggunakan pendekatan dari atas ke bawah, diperoleh :

$\mathrm{T}=\mathrm{G} 1$ + G2 (karena $\mathrm{G} 1=\mathrm{G} 3$ + G4 dan $\mathrm{G} 2=\mathrm{G} 5=\mathrm{S} 1$ ) 
Budiawan, W., Ulfa, E. A., Andarani, P.

Analisis Hubungan Kebisingan Mesin Dengan Stres

Kerja

$=\mathrm{G} 3+\mathrm{G} 4+\mathrm{S} 1$ (karena $\mathrm{G} 3=\mathrm{G} 6=\mathrm{G} 8$ + $\mathrm{G} 9$ dan $\mathrm{G} 4=\mathrm{G} 7=\mathrm{P} 1$ )

$=\mathrm{G} 8+\mathrm{G} 9+\mathrm{P} 1+\mathrm{S} 1$ (karena $\mathrm{G} 8=\mathrm{G} 10=$ $\mathrm{P} 2+\mathrm{P} 3$ dan $\mathrm{G} 9=\mathrm{P} 4)$

$=\mathrm{P} 2+\mathrm{P} 3+\mathrm{P} 4+\mathrm{P} 1+\mathrm{S} 1$

Maka minimal cut set dari Gambar 3 adalah $\{\mathrm{P} 1\},\{\mathrm{P} 2\},\{\mathrm{P} 3\},\{\mathrm{P} 4\},\{\mathrm{S} 1\}$.

\section{Analisis Kualitatif}

Analisis Kualitatif adalah kombinasi kegagalan yang menyebabkan top event pada suatu sistem atau minimal cut set itu sendiri. Dari minimal cut set dapat diketahui berapa banyak kejadian yang dapat langsung menyebabkan top event terjadi. (Priyatna, 2000). Hasil Analisis kualitatif dari FTA sumber kebisingan TFO dengan top event adalah kebisingan mesin TFO yang terjadi jika kejadian di bawah ini terjadi, yaitu kejadian :

a. Lupa memberi minyak pelumas

b. Seal Katup Oli Bocor

c. Bearing tidak diganti (masa ekonomis 2 tahun)

d. Traveller tidak diganti (masa ekonomis 10 hari)

e. Mesin Doubling bermasalah

Dengan mengetahui penyebab penyebab yang mengakibatkan stres kerja operator mesin TFO, sehingga bisa untuk mengatasi stres kerja pada operator mesin TFO dapat dilakukan pengurangan tingkat kebisingan dengan melakukan pencegahan dan perawatan mesin TFO dengan menekankan pada bagian-bagian mesin seperti diatas.

\section{Analisis Kuantatif}

Analisis Kuantitaf dilakukan untuk menaksir probabilitas dari kejadian yang akan diselidiki. Salah satu metode untuk menaksir probabilitas dari resik adalah Probabilistic Risk Assesment (PRA) (Stamatelos dan Caraballo, 2002). Analisis kuantitatif dari FTA memberikan manfaat khusus, namun sebagai gabungan dari minimal cut set. Maka probabilitas dari top event dapat ditaksir dengan penjumlahan dari probabilitas masing- masing cut set. Diketahui probabilitas kegagalan pada masing-masing basic event (Pandey, 2005) seperti terlihat di Tabel 2.
Tabel 2. Probabilitas Kegagalan

\begin{tabular}{clc} 
Simbol & \multicolumn{1}{c}{ Deskripsi } & Probabilitas \\
\hline P1 & $\begin{array}{l}\text { Traveller tidak diganti } \\
\text { (masa ekonomis 10 } \\
\text { hari) }\end{array}$ & 0,01 \\
\hline P2 & $\begin{array}{l}\text { Lupa memberi minyak } \\
\text { pelumas }\end{array}$ & 0,01 \\
\hline P3 & Seal Katup Oli Bocor & 0,01 \\
\hline P4 & $\begin{array}{l}\text { Bearing tidak diganti } \\
\text { (masa ekonomis 2 } \\
\text { tahun) }\end{array}$ & 0,01 \\
\hline S1 & $\begin{array}{l}\text { Mesin Doubling } \\
\text { bermasalah }\end{array}$ & 0,001
\end{tabular}

Minimal cut set yang didapat dari analisis kuantitatif adalah $\{P 1\},\{P 2\},\{P 3\}$, $\{\mathrm{P} 4\},\{\mathrm{S} 1\}$ Maka dari probabilitas basic event diatas, didapat probabilitas top event $(\mathrm{T})$ terjadi adalah

$$
\begin{aligned}
\mathrm{T} & =\mathrm{P} 1+\mathrm{P} 2+\mathrm{P} 3+\mathrm{P} 4+\mathrm{S} 1 \\
& =0,01+0,01+0,01+0,01+0,001 \\
& =0,041
\end{aligned}
$$

Maka probabilitas munculnya stres kerja operator mesin TFO akibat kebisingan mesin TFO dari probabilitas yang diketahui 0,041 . Angka ini menunjukkan sistem tersebut dalam keadaan layak digunakan. Jika angka probabilitas mendekati 1 , sistem tidak layak digunakan.

\section{KESIMPULAN}

Penelitian ini menyimpulkan bahwa, berdasarkan Uji korelasi Spearman dengan menggunakan software SPSS 16, diperoleh hasil bahwa tingkat kebisingan mesin TFO dengan stres kerja operator mesin TFO memiliki hubungan yang kuat dengan Correlation Coeficient mendekati 1 yaitu 0,829 dan Significant 2-tailed (dwi sisi) ( $p$ value) $<0.05$, yaitu 0,042 .

Upaya untuk mengurangi tingkat kebisingan sehingga akan menggurangi stres kerja bagi para pekerja. Dengan menggunakan analisis menggunakan Fault Tree Analysis (FTA) sumber kebisingan untuk mengetahui sumber kebisingan. Berdasarkan analisis kualitatif FTA sumber kebisingan, penyebab kebisingan : lupa memberi minyak pelumas, seal katup oli bocor, bearing tidak diganti (masa ekonomis 2 tahun), traveller tidak diganti (masa ekonomis 10 hari), dan mesin Doubling 
bermasalah. Berdasarkan analisis kuantitatif probabilitas munculnya stres kerja operator mesin TFO akibat kebisingan mesin TFO dari probabilitas yang diketahui 0,041. Angka ini menunjukkan sistem tersebut dalam keadaan layak digunakan. Jika angka probabilitas mendekati 1 , sistem tidak layak digunakan.

\section{DAFTAR PUSTAKA}

EU-OSHA (European Union-Occupational Safety and Health Administration) European Agency for Safety and Health at Work. (2005). The Impact of Noise at Work. FACTS-57. <http://ew2005.osha.eu.int> Diakses April 2016.

Halil, I. S., Russeng, S. S. dan Saleh, L. M. (2009). Stres Kerja Pada Operator Mesin Pembangkit Listrik Di PT. PLN (Persero) Sektor Tello Makassar. Jurnal MKMI.

Harrianto, R. (2010). Buku Ajar Kesehatan Kerja. Jakarta: Kedokteran EGC.

Nawawinetu, E. D. dan Adriyani, R. (2007). Stres Akibat Kerja Pada Tenaga Kerja
Yang Terpapar Bising. The Indonesian Journal Of Public Health.

NIOSH (National Institute for Occupational Safety and Health). (2010). Occupationally Induced Hearing Loss. DHHS (NIOSH) Publication Number 2010-136.

Pandey, M. (2005). Engineering and Sustainable Development: Fault Tress Analysis. Waterloo : University of Waterloo.

Priyanta, D. (2000). Keandalan dan Perawatan : Modul 1 Probabilitas. Surabaya : Institut Teknologi Sepuluh November.

Stamatelos, M. dan Caraballo, J. (2002). Fault Tree Handbook Worth Aerospace Application. Washington D.C.

Vesely, W. E. dan Goldberg, F. F. (1981). Fault Tree Handbook. Washington D.C : U.S. Nuclear Regulatory Commision.

WHO (World Health Organization). (2011). Burden disease from environmental noise: Quantification of healthy life years lost in Europe. WHO Noise Data and Facts. 